\title{
Results of Destructive Analysis in Developed Rice Genotypes
}

\author{
M. Chandrika ${ }^{1 *}$, A. Siva Sankar ${ }^{2}$, C.H. Surender Raju ${ }^{3}$ and S. Narender Reddy ${ }^{4}$ \\ ${ }^{1}$ Department of Crop Physiology, College of Agriculture, PJTSAU, Rajendranagar, \\ Hyderabad-500030, Telangana, India \\ ${ }^{2}$ Department Comptroller of Examination ANGRAU, India \\ ${ }^{3}$ Plant Breeding, ARI, India \\ ${ }^{4}$ Department of Crop Physiology, PJTSAU, Rajendranagar, Hyderabad-500030, Telangana, India
}

*Corresponding author

\section{A B S T R A C T}

\begin{tabular}{|l|}
\hline Ke y w o r d s \\
$\begin{array}{l}\text { Developed rice } \\
\text { genotypes, Dry matter, } \\
\text { Leaf area } \\
\text { measurement and Root } \\
\text { parameters. }\end{array}$ \\
\hline Article Info \\
\hline $\begin{array}{l}\text { Accepted: } \\
\text { 21 September } 2017 \\
\text { Available Online: } \\
\text { 10 October } 2017\end{array}$ \\
\hline
\end{tabular}

Keywords

Developed rice genotypes, Dry matter, parameters.

\section{Introduction}

Rice (Oryza sativa L.) is one of the most important cereal crops of family Poaceae. It is the staple food crop of 60 per cent of the world's population. The edible uses of rice include rice flakes, puffed rice and canned rice. Itis also used in starch and brewing industries. By products of rice milling i.e., rice husk and bran are used as cattle and poultry feed. Rice is one of the diverse crop grow in different agro-climatic conditions and it is the second largest produced cereal in the world. More than 90 percent of the world's rice area is in Asia, which is the home for more than half of world's poor and more than half of world's rice cultivators (Rao et al., 2010).

India is the second largest producer and consumer of rice in the world. Its production in India crossed the mark of 100 million tons in 2011-12 accounting for $22.81 \%$ of global production in that year. The productivity of rice has increased from $1984 \mathrm{~kg} / \mathrm{ha}$ in $2004-$ 05 to $2372 \mathrm{~kg} / \mathrm{ha}$ in 2011-12. Rice is grown in an area of $44.8 \mathrm{~m}$ ha with the production and productivity levels of 99.18 mtones and 
$2214 \mathrm{~kg} / \mathrm{ha}$, respectively in India. In Andhra Pradesh rice is grown in an area of 43.75 lakh ha with the production and productivity levels of 142.1 lakh tones and $3248 \mathrm{~kg} / \mathrm{ha}$ (Anonymous, 2011). In crop improvement programs, continues efforts were on going in development of high yielding improved new varieties and management practices aiming at rice productivity.

Among the rice genotypes cultivated in our country, the developed rice varieties are popular over the recent year. These rice varieties are essential and to have throughout knowledge on physiological parameters in view of this experiment was conducted to study the dry matter, Leaf area measurement and root parameters.

\section{Materials and Methods}

An experiment was conducted during rabi season 2014-15 at Student Farm, College on Agriculture, Rajendranagar, Hyderabad, with eleven rice genotypes.

The experiment was laid out by following randomized block design with three replications. 30days of old nursery was transplanted by following a spacing of $15 \times$ $15 \mathrm{~cm}$. Nitrogen, phosphorus and potassium were applied at the rate 100:60:40 N, $\mathrm{P}_{2} \mathrm{O}_{5}$, $\mathrm{K}_{2} \mathrm{O} \mathrm{Kg} \mathrm{ha}{ }^{-1}$ in the form of urea, SSP and MOP. Scheduled irrigation and weed management practices were followed later harvesting were done. Destructive samplings were done at fort night interval by uprooting five hill per plot. Leaf area was measuring by using LI-3100 leaf area meter (LICOR Lincoln, Nebraska, USA). Dry matter of the component parts was recorded by subjecting the sample at $700 \mathrm{C}$ temperature in hot air oven till constant weight was obtained. After complete drying, dry matter was expressed in $\mathrm{gm}^{-2}$.Root length was measured using a standard scale from the ground level to the tip of the root. Root volume was measured by water displacement method by dipping the properly washed root in a $1000 \mathrm{ml}$ measuring cylinder containing water up to a certain point. Root volume was determined by displaced water (in $\mathrm{ml}$ ) in the cylinder after root dipping. Mean of five values was obtained and expressed as root length and volume per hill respectively.

\section{Results and Discussion}

Total dry matter $\left(\mathrm{g} \mathrm{m}^{-2}\right)$ for rice genotypes presented in table 1 and depicted in figure 1 have shown significant difference among all the rice genotypes from 30 DAT to maturity. There was a steady increase in total dry matter production in all the stages till maturity. The highest dry matter production of $1707 \mathrm{~g} \mathrm{~m}^{-2}$ was recorded in genotype RNR 15038 while minimum dry matter production of $1296 \mathrm{~g} \mathrm{~m}^{-2}$ was recorded for the genotype Rajendra at 90 DAT. The highest dry matter production in genotype RNR 15038 than in other genotype can be attributed to more LAI, LAD and better crop growth rates recorded with this genotype. Similar results were also reported by Chandrashekar et al., (2001), Sinha et al., (2009) and Wu Gui et al., (2010).

Present study confirms the views of Venkateshwarulu and Prasad (1982) that the plant with greater dry matter accumulation could be expected to have a greater seed yield for plant as production of total dry matter is the prerequisite seed yield. Results showed that there was comparatively higher dry matter production after heading that conforms the study of Weng et al., (1984).

Data on leaf area index (LAI) for all rice genotypes are presented in table 1 and depicted in figure 2. A significant variation was observed in LAI among rice genotypes from 30 DAT to maturity. These variations could be ascribed to genetic, climatic, and 
nutritional factor as supported by Venkateshwarulu and Maduley (1976) and this study also conformed the result of Shahidullah et al., (2009) who stated that different rice genotypes exhibited significant variations for leaf area index (LAI).

It was observed that LAI increased from 15 DAT to 60 DAT behind which declined sharply and similar results were also found by Shiv kumar and Haloi (2001) and Chandrashekar et al., (2001). Maximum leaf area index of 7.12 was reported in genotype RNR 15038 and minimum of 3.71 was reported with NLR 34449 at 60 DAT.
The decreased in the leaf area index towards maturity may be due to lesser number of leaves as a result of senescence of older leaves. In rice, yield increased with increase in LAI (Pinheiro and Guimaraes, 1990., Sahoo and Guru, 1998).

There was significant variation for root length among the tested genotypes of developed rice. Root length increased gradually up to 75 DAT after that the increase was very negligible. (Table 3 and figure 3). Maximum root length of $31.6 \mathrm{~cm}$ in genotype RNR 15038 and minimum of $18.5 \mathrm{~cm}$ were recorded genotype Swarna respectively at $90 \mathrm{DAT}$.

Table.1 Total dry matter productive $\left(\mathrm{g} \mathrm{m}^{-2}\right)$ at different growth stages in rice genotypes during rabi season

\begin{tabular}{|c|c|c|c|c|c|c|c|}
\hline \multirow{2}{*}{ S.No } & \multirow{2}{*}{ Genotypes } & \multicolumn{6}{|c|}{ Days after transplanting } \\
\cline { 3 - 8 } & & $\mathbf{1 5}$ & $\mathbf{3 0}$ & $\mathbf{4 5}$ & $\mathbf{6 0}$ & $\mathbf{7 5}$ & $\mathbf{9 0}$ \\
\hline 1 & Tellahamsa & 84 & 311 & 555 & 1011 & 1371 & 1476 \\
\hline 2 & KNR-118 & 63 & 265 & 514 & 986 & 1304 & 1450 \\
\hline 3 & TN-1 & 63 & 262 & 505 & 906 & 1273 & 1429 \\
\hline 4 & JGL 11118 & 74 & 322 & 585 & 1101 & 1485 & 1654 \\
\hline 5 & RNR 15048 & 56 & 264 & 571 & 1067 & 1474 & 1626 \\
\hline 6 & Swarna & 80 & 231 & 490 & 970 & 1248 & 1359 \\
\hline 7 & MTU 1010 & 77 & 312 & 587 & 1079 & 1427 & 1593 \\
\hline 8 & RNR 15038 & 58 & 308 & 609 & 1129 & 1495 & 1707 \\
\hline 9 & HR 12 & 76 & 294 & 452 & 890 & 1153 & 1301 \\
\hline 10 & NLR 34449 & 72 & 243 & 481 & 831 & 1211 & 1345 \\
\hline 11 & Rajendra & 65 & 267 & 527 & 937 & 1201 & 1296 \\
\hline & SE \pm & 3.20 & 2.17 & 5.18 & 9.46 & 20.66 & 22.6 \\
\hline & C.D. & NS & 18.14 & 15.30 & 54.62 & 61.40 & 84.05 \\
\hline
\end{tabular}


Table.2 Leaf area index (LAI) at different growth stages in rice genotypes during rabi season

\begin{tabular}{|c|c|c|c|c|c|c|c|}
\hline \multirow{2}{*}{ S.No } & \multirow{2}{*}{ Genotypes } & \multicolumn{7}{|c|}{ Days after transplanting } \\
\cline { 3 - 8 } & & $\mathbf{1 5}$ & $\mathbf{3 0}$ & $\mathbf{4 5}$ & $\mathbf{6 0}$ & $\mathbf{7 5}$ & $\mathbf{9 0}$ \\
\hline 1 & Tellahamsa & 0.36 & 4.06 & 4.61 & 5.03 & 2.81 & 1.35 \\
\hline 2 & KNR-118 & 0.28 & 2.18 & 5.29 & 5.77 & 4.81 & 2.04 \\
\hline 3 & TN-1 & 0.35 & 2.20 & 4.80 & 5.15 & 2.22 & 1.45 \\
\hline 4 & JGL 11118 & 0.27 & 2.64 & 4.39 & 4.78 & 3.58 & 1.88 \\
\hline 5 & RNR 15048 & 0.27 & 2.80 & 5.49 & 6.16 & 4.54 & 2.27 \\
\hline 6 & Swarna & 0.34 & 4.13 & 4.67 & 5.10 & 2.89 & 1.36 \\
\hline 7 & MTU 1010 & 0.28 & 2.21 & 5.72 & 5.78 & 4.65 & 2.79 \\
\hline 8 & RNR 15038 & 0.31 & 2.26 & 6.56 & 7.12 & 4.99 & 2.28 \\
\hline 9 & HR 12 & 0.35 & 2.32 & 4.52 & 5.02 & 4.27 & 1.64 \\
\hline 10 & NLR 34449 & 0.30 & 2.30 & 3.61 & 3.71 & 2.39 & 1.45 \\
\hline 11 & Rajendra & 0.40 & 3.61 & 4.89 & 5.37 & 3.06 & 1.43 \\
\hline & SE \pm & $\mathbf{0 . 0 1}$ & $\mathbf{0 . 0 3}$ & $\mathbf{0 . 1 0}$ & $\mathbf{0 . 1 3}$ & $\mathbf{0 . 0 3}$ & $\mathbf{0 . 0 2}$ \\
\hline & C.D. & NS & NS & $\mathbf{0 . 3 0}$ & $\mathbf{0 . 4 2}$ & $\mathbf{0 . 3 1}$ & NS \\
\hline
\end{tabular}

Table.3 Root length $(\mathrm{cm})$ at different growth stages in rice genotypes during rabi season

\begin{tabular}{|c|c|c|c|c|c|c|c|}
\hline \multirow{2}{*}{ S.N0 } & \multirow{2}{*}{ Genotypes } & \multicolumn{7}{|c|}{ Days after transplanting } \\
\cline { 3 - 8 } & & $\mathbf{1 5}$ & $\mathbf{3 0}$ & $\mathbf{4 5}$ & $\mathbf{6 0}$ & $\mathbf{7 5}$ & $\mathbf{9 0}$ \\
\hline 1 & Tellahamsa & 13.3 & 24.4 & 26.5 & 28.6 & 28.4 & 28.9 \\
\hline 2 & KNR-118 & 12.6 & 20.8 & 22.3 & 25.3 & 25.3 & 25.4 \\
\hline 3 & TN-1 & 12.5 & 23.6 & 25.5 & 29.2 & 29.3 & 29.4 \\
\hline 4 & JGL 11118 & 14.76 & 24.1 & 26.1 & 30.2 & 30.3 & 33.7 \\
\hline 5 & RNR 15048 & 17.02 & 25.3 & 28.4 & 31.4 & 31.5 & 31.6 \\
\hline 6 & Swarna & 10.1 & 15.2 & 17.9 & 18.3 & 18.4 & 18.5 \\
\hline 7 & MTU 1010 & 13.2 & 25.8 & 27.4 & 29.3 & 29.4 & 29.5 \\
\hline 8 & RNR 15038 & 18.4 & 27.2 & 29.6 & 32.5 & 31.6 & 32.7 \\
\hline 9 & HR 12 & 13.4 & 22.6 & 24.5 & 28.5 & 28.6 & 28.7 \\
\hline 10 & NLR 34449 & 12.6 & 23.3 & 24.3 & 26.5 & 26.3 & 26.6 \\
\hline 11 & Rajendra & 12.26 & 20.5 & 23.1 & 24.5 & 24.6 & 24.7 \\
\hline & SE \pm & $\mathbf{0 . 2 8}$ & $\mathbf{0 . 2 9}$ & $\mathbf{0 . 3 0}$ & $\mathbf{0 . 3 2}$ & $\mathbf{1 . 0 8}$ & $\mathbf{0 . 3 2}$ \\
\hline & C.D. & $\mathbf{0 . 8 3}$ & $\mathbf{0 . 8 5}$ & $\mathbf{0 . 9 0}$ & $\mathbf{0 . 9 5}$ & $\mathbf{3 . 1 9}$ & $\mathbf{0 . 9 5}$ \\
\hline
\end{tabular}


Table.4 Root volume (RV) ( $\left.\mathrm{ml} \mathrm{hill}^{-1}\right)$ at different growth stages in rice genotypes during rabi season

\begin{tabular}{|c|c|c|c|c|c|c|}
\hline \multirow{2}{*}{ S.N0 } & \multirow{2}{*}{ Genotypes } & \multicolumn{5}{|c|}{ Days after transplanting } \\
\cline { 3 - 7 } & & $\mathbf{3 0}$ & $\mathbf{4 5}$ & $\mathbf{6 0}$ & $\mathbf{7 5}$ & $\mathbf{9 0}$ \\
\hline 1 & Tellahamsa & 21.7 & 22.9 & 26.5 & 27.4 & 21.6 \\
\hline 2 & KNR-118 & 19.4 & 22.8 & 26.6 & 28.1 & 24.6 \\
\hline 3 & TN-1 & 12.2 & 17.5 & 22.4 & 22.6 & 20.8 \\
\hline 4 & JGL 11118 & 17.3 & 21.8 & 30.3 & 31.2 & 25.4 \\
\hline 5 & RNR 15048 & 18.2 & 22.8 & 31.7 & 31.3 & 26.5 \\
\hline 6 & Swarna & 13.2 & 17.9 & 22.3 & 23.4 & 21.3 \\
\hline 7 & MTU 1010 & 18.4 & 21.7 & 28.3 & 30.6 & 23.4 \\
\hline 8 & RNR 15038 & 24.2 & 26.4 & 33.2 & 32.7 & 27.7 \\
\hline 9 & HR 12 & 10.2 & 16.2 & 20.1 & 21.4 & 20.5 \\
\hline 10 & NLR 34449 & 15.4 & 21.60 & 27.9 & 26.2 & 22.8 \\
\hline 11 & Rajendra & 15.1 & 20.16 & 26.5 & 25.6 & 21.9 \\
\hline & SE \pm & $\mathbf{0 . 6 3}$ & $\mathbf{0 . 7 1}$ & $\mathbf{1 . 1 8}$ & $\mathbf{1 . 0 2}$ & $\mathbf{0 . 6 9}$ \\
\hline & C.D. & $\mathbf{1 . 8 7}$ & $\mathbf{2 . 1 1}$ & $\mathbf{3 . 4 9}$ & $\mathbf{3 . 0}$ & $\mathbf{2 . 0 6}$ \\
\hline
\end{tabular}

Table.5 Root weight $\left(\mathrm{g} \mathrm{hill}^{-1}\right.$ ) at different growth stages in rice genotypes during rabi season

\begin{tabular}{|c|c|c|c|c|c|c|c|}
\hline \multirow{2}{*}{ S.N0 } & \multirow{2}{*}{ Genotypes } & \multicolumn{7}{|c|}{ Days after transplanting } \\
\cline { 3 - 8 } & & $\mathbf{1 5}$ & $\mathbf{3 0}$ & $\mathbf{4 5}$ & $\mathbf{6 0}$ & $\mathbf{7 5}$ & $\mathbf{9 0}$ \\
\hline 1 & Tellahamsa & 0.16 & 0.38 & 2.19 & 4.22 & 4.35 & 5.32 \\
\hline 2 & KNR-118 & 0.14 & 0.35 & 0.89 & 2.46 & 3.26 & 3.45 \\
\hline 3 & TN-1 & 0.18 & 0.65 & 1.22 & 1.84 & 2.15 & 2.21 \\
\hline 4 & JGL 11118 & 0.20 & 0.71 & 1.10 & 2.11 & 2.21 & 2.39 \\
\hline 5 & RNR 15048 & 0.12 & 2.21 & 2.98 & 4.32 & 5.23 & 5.34 \\
\hline 6 & Swarna & 0.13 & 0.65 & 1.85 & 2.54 & 2.93 & 3.09 \\
\hline 7 & MTU 1010 & 0.38 & 1.89 & 3.12 & 4.71 & 5.45 & 5.37 \\
\hline 8 & RNR 15038 & 0.79 & 2.26 & 3.73 & 5.31 & 5.56 & 6.03 \\
\hline 9 & HR 12 & 0.54 & 1.18 & 1.56 & 2.28 & 2.68 & 2.87 \\
\hline 10 & NLR 34449 & 0.30 & 0.97 & 1.38 & 2.20 & 2.29 & 2.47 \\
\hline 11 & Rajendra & 0.89 & 1.35 & 2.62 & 3.12 & 3.22 & 3.38 \\
\hline & SE \pm & $\mathbf{0 . 0 3}$ & $\mathbf{0 . 0 1}$ & $\mathbf{0 . 0 2}$ & $\mathbf{0 . 0 3}$ & $\mathbf{0 . 0 5}$ & $\mathbf{0 . 1 5}$ \\
\hline & C.D. & $\mathbf{0 . 1 1}$ & $\mathbf{0 . 0 6}$ & $\mathbf{0 . 1 1}$ & $\mathbf{0 . 2 3}$ & $\mathbf{0 . 1 7}$ & $\mathbf{0 . 4 6}$ \\
\hline
\end{tabular}


Fig.1 Total dry matter production at different growth stages in rice genotypes during rabi season

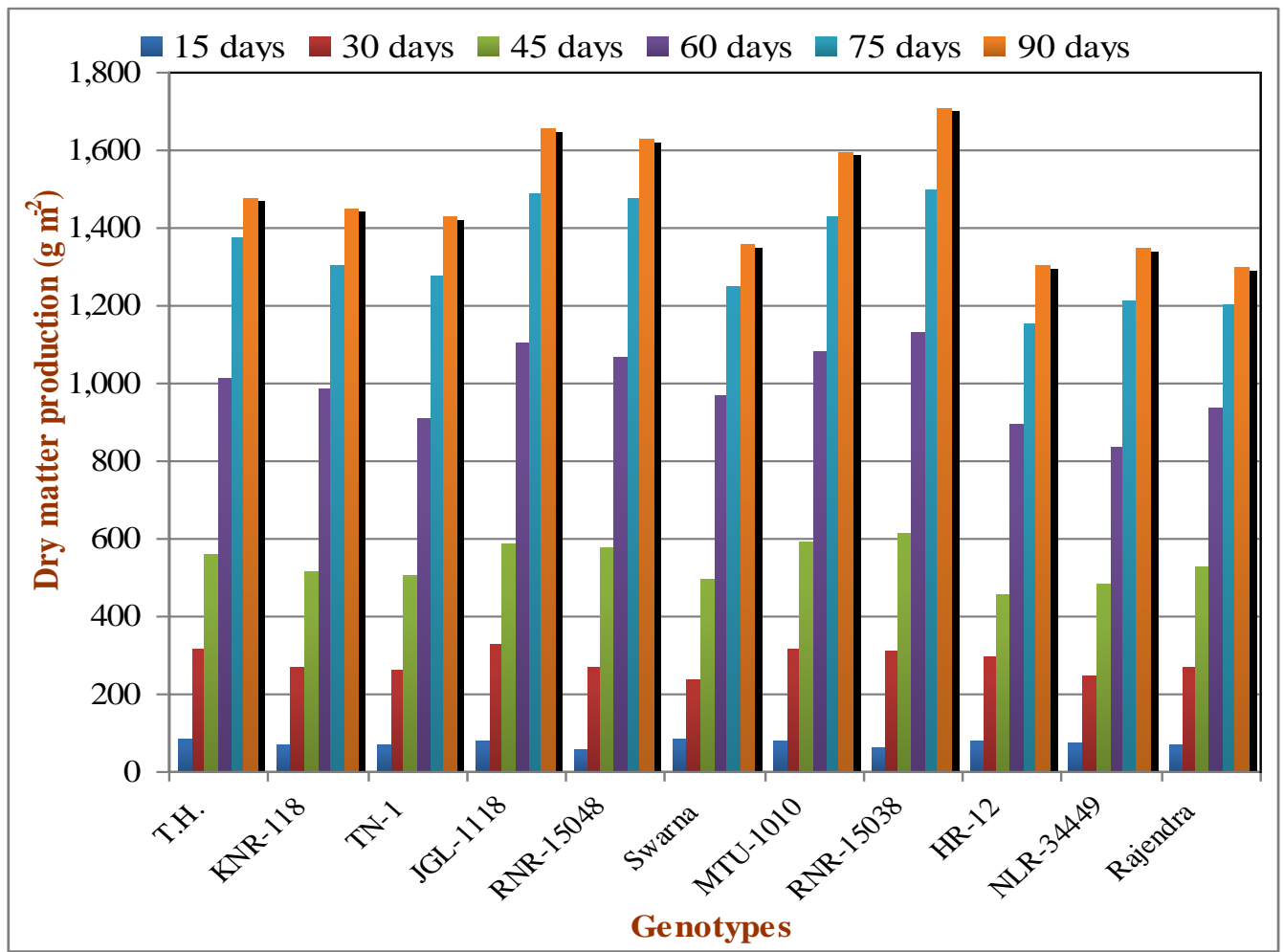

Fig.2 Leaf area index at different growth stages in rice genotypes during rabi season

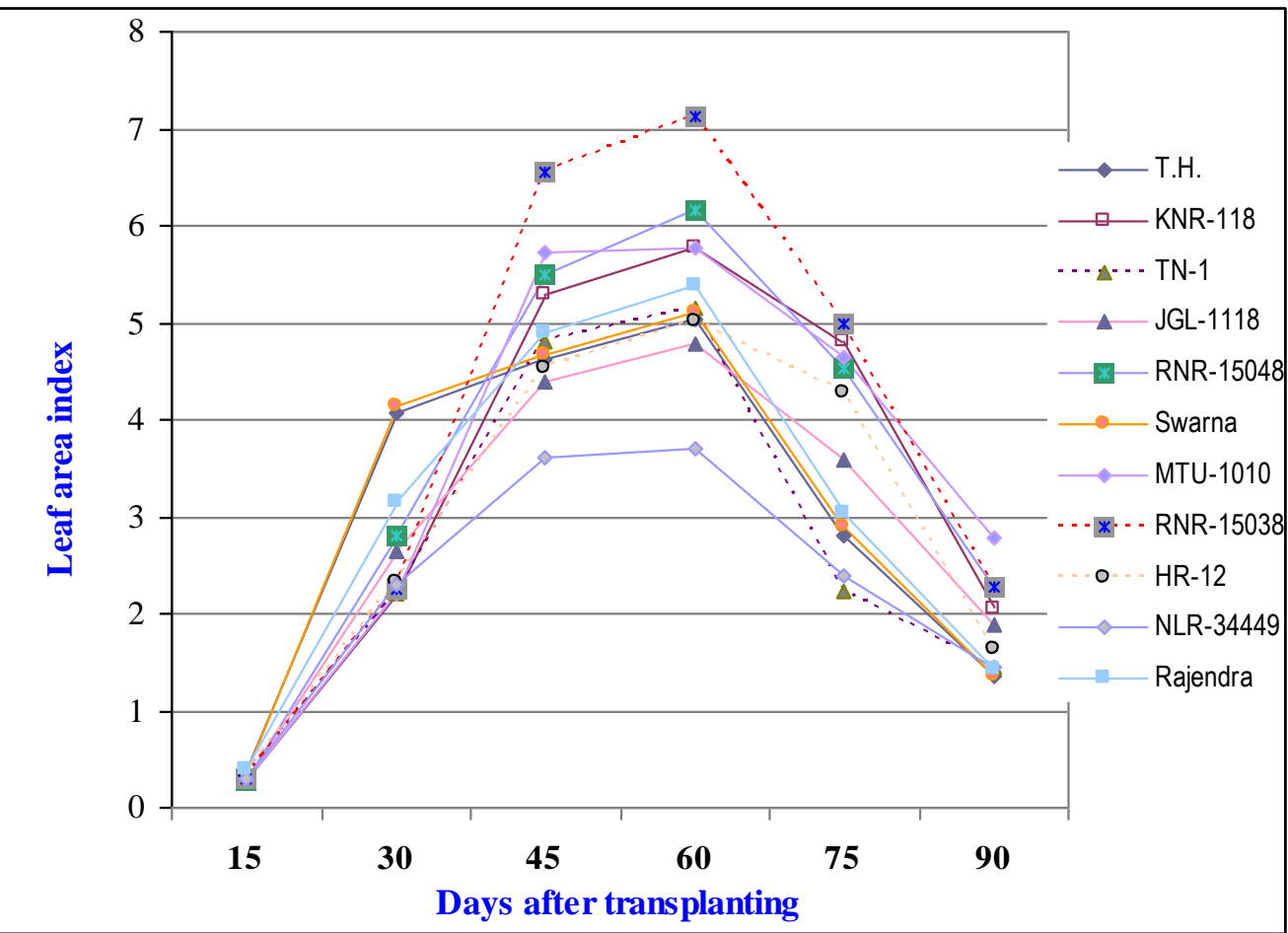


Fig.3 Root length at different growth stages in rice genotypes during rabi season

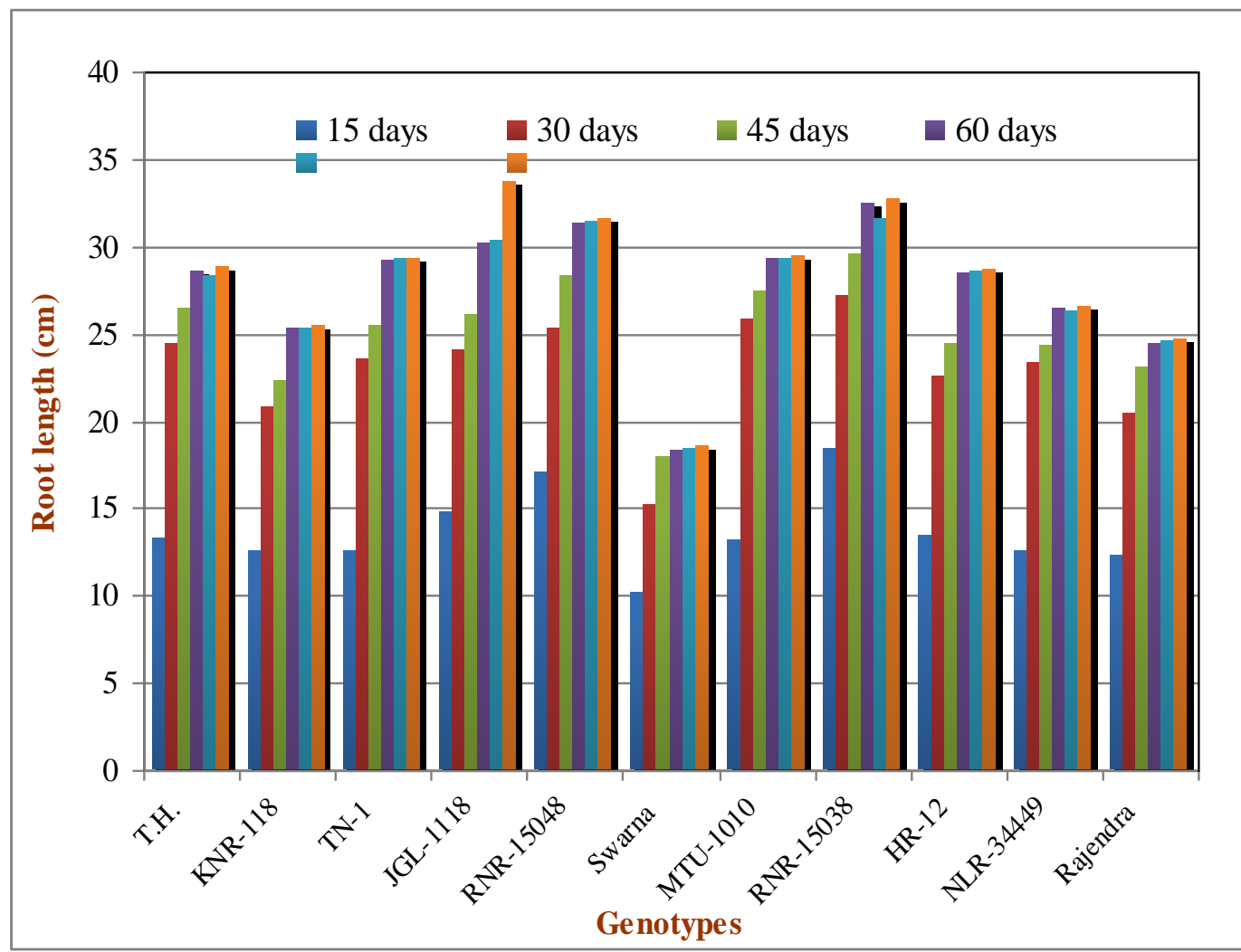

Fig.4 Root volume at different growth stages in rice genotypes during rabi season

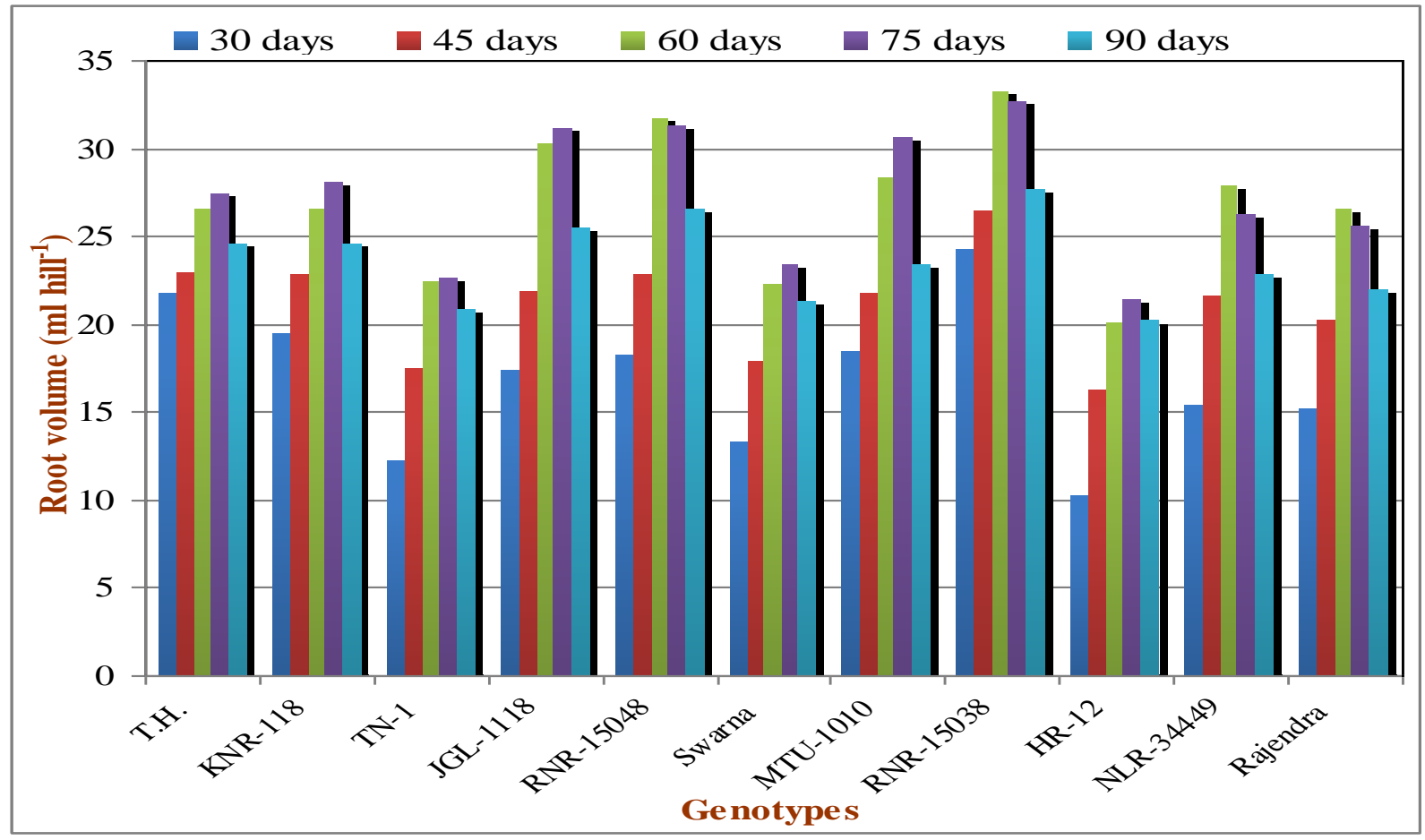


Fig.5 Root weight at different growth stages in rice genotypes during rabi season

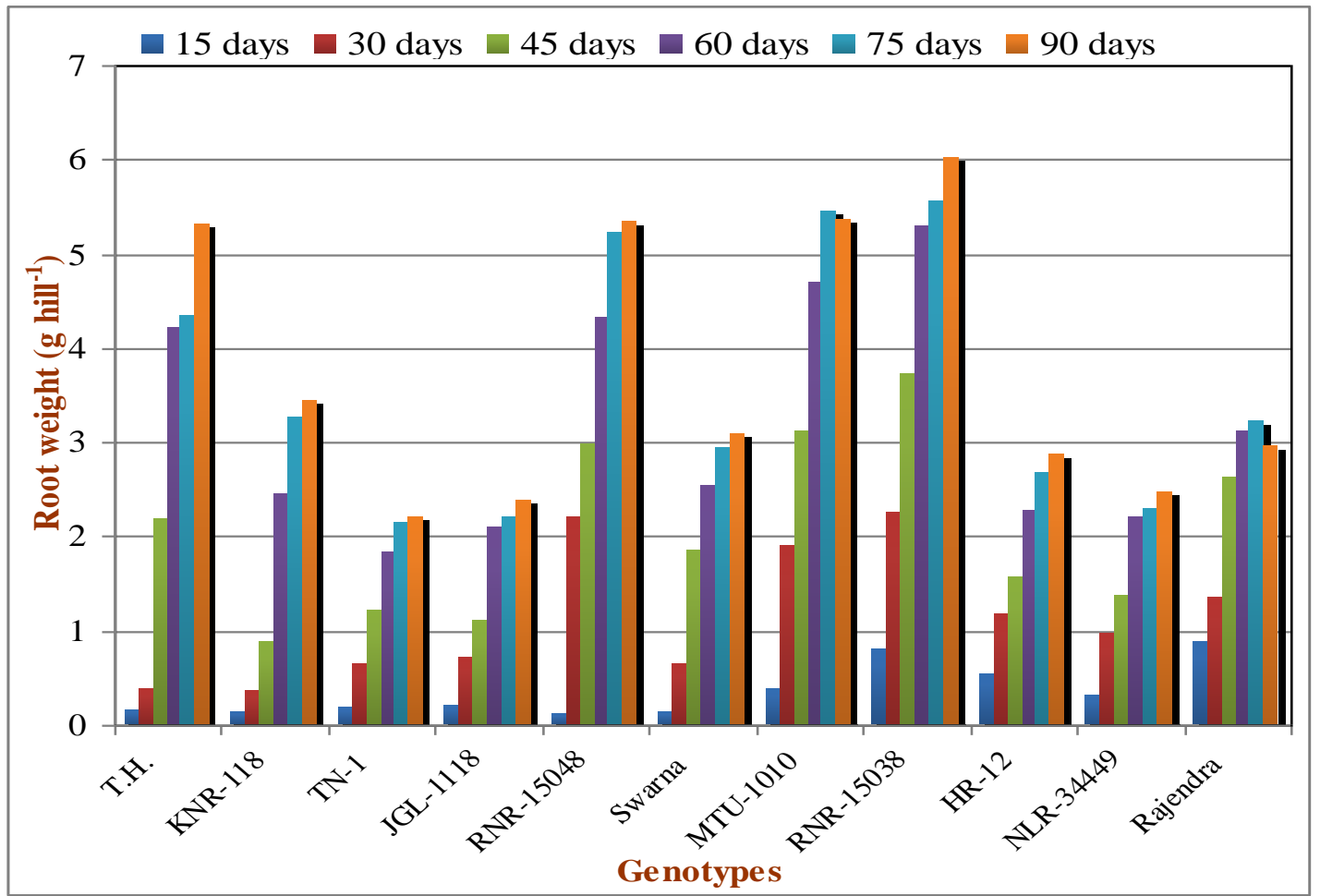

Similar results were reported by Rajesh et al., (2008). They further showed that higher root length positively associated with grain yield and dry matter protection. Kanbar et al., (2009) revealed that root to shoot length ratios had large effect on shoot dry weight and grain yield under well-watered condition.

Root volume showed significant variation among genotypes at 30,60 and 90 DAT. The progressive increase was noticed in root volume in all the genotypes up to 60 DAT thereby declined till maturity (Table 4 and figure 4 ). Maximum root volume of $33.2 \mathrm{ml} \mathrm{hill}^{-1}$ was recorded in RNR 15038 at 60 DAT and minimum of $20.1 \mathrm{ml} \mathrm{hill}^{-1}$ was observed in genotype HR-12 among the stages analysed and among the genotypes studied. Root volume and root weight determined the ability of a plant to exploit the resources such as nutrient supply, moisture etc. so contributed to the grain yield and total dry matter production was reported by Rajesh et al., (2008). Similarly Zuno-Altoverso et al., (1990) found that root volume was significantly and positively correlated with both root length and root weight.

Data on root dry weight are presented in table 5 and depicted in figure 5. Root dry weight showed significant variation among the aromatic genotypes from 30 DAT to maturity. There was progressive increase in root weight among all the genotype up to 60 DAT thereafter declined till maturity. Maximum root dry weight of $5.36 \mathrm{~g}$ hill was recorded in RNR 15038 And minimum root dry weight of $1.83 \mathrm{~g}$ hill was observed in TN-1 at 60 DAT. Genotypes with better developed roots, particularly with advantageous root morphology such as higher root weight with greater root volume together with increased root length enable nutrients acquisition from deeper soil depth hence increase the yield. Positive correlation between the root weight and grain yield and dry matter production was also reported by Rajesh et al., (2008), Kanber et al., (2009) and Fan JianBo et al., (2010). 
Based on the above results it is concluded that, significant variation was observed for root length, root volume and weight among the rice genotypes studied. Root length increased gradually up to 75 DAT after that the increased was very negligible. Maximum root length was recorded in variety 15038 throughout the crop growth and minimum in variety swarna. Root volume and weight increased up to 60 DAT thereafter declined till maturity. Maximum root volume and root weight was recorded in RNR 15038 at all growth stages and minimum was HR-12. There was positive association between high root volume and root weight with grain yield and dry matter production. There was a significant increase in total dry weight in all stages till maturity. The highest dry matter production was recorded in variety RNR 15038 while minimum was recorded in variety Rajendra. LAI increased from 15 DAT to 60 DAT and later on declined. Variest variation in leaf area index

\section{References}

Chandrasekhar, J., Rama rao, G., Ravindranatha Redd, B and reddy, K.B. 2001. Physiological analysis of growth and productivity in hybrid rice. Indian $J$. Plant physiol. 6(2): 142-146.

Kanbar, A., Toorchi, $M$ and Shashidhar, H.E.2009. Title Relationship between root and yield morphological characters in rainfed low land rice (Oryza sativa L.). Cereal Research Communicatrions. 37(2): 261-268.

Pinherio, B., das and Guimares, E.P.1990. Leaf area index and productivity in upland rice. 1. Limiting levels. Pesquisa Agropecuaria Brasilera. 25(6): 863-872.

Rajesh Kumar, Verma, A.K., Kamleshwar Kumar and Ravi Kumar. 2008. Morphological analysis of yield in different rice genotype. Journal of Research (BAU). 20(1): 37-43.

Rao, K. V., Singh, S. P., Surekha, K. and Muthuraman, P. 2010. Site specific integrated nutrient management in rice and rice based cropping systems. Indian Agricultural Research, Directorate of Rice Research. pp: 1-2.

Sahoo, N.C., and Guru, S.K. 1998. Physiological basis of yield variation in short duration cultivars of rice. Indian Journal of Plant Physiology. 3(1): 36-41.

Shahidullah, S.M., Hanaf, M.M., Ashrafuzzaman, M., Razi Ismail, $M$ and Salam, M.A.2009. Phenological characters and genetic divergence in aromatic rice. African Journal of Biotechnology. 8(14): 3199-3207.

Sinha, A.C., Kairi, P., Patra, P.S and De, B. 2009. Performance of aromatic rice varieties under terai region of West Bengal. Journal of Crop Science and Weed. 5(1): 285-287.

Venkateshwarlu, B., and Prasad, A.S.R. 1982. Nature of association among biomass, harvest index and economical yield in rice. Harvest index and biomass: Criteria for selecting plants with high yielding ability. Indian Journal of Plant Physiology. 25: 149.

Weng, R. X., 1984. Effects of carbohydrates stored before heading stage and dry matter production on the rice grain. Agron Abroad. Rice. 2: 40-49.

Wu GuiCheng, Cheng, H. Z., QiGen, D., Yang, H. Z., Xu Ke, Gao Hui, HaiYan, W. AnQin, S., ZongJin, X., ZongHua, Q and JuYing, S. 2010. Characteristics of dry matter production and accumulation and Super-High yield of Japonica super rice in south China. Acta Agronomica Sinica. Rice in south China. Acta Agronomica Sinica. 36:11.

\section{How to cite this article:}

Chandrika, M., A. Siva Sankar, C.H. Surender Raju and Narender Reddy, S. 2017. Results of Destructive Analysis in Developed Rice Genotypes. Int.J.Curr.Microbiol.App.Sci. 6(10): 23602368. doi: https://doi.org/10.20546/ijcmas.2017.610.278 